\title{
Epithelioid Variant of High-Grade Myxofibrosarcoma in the False Vocal Fold: A Case Report
}

\author{
Seulki Song ${ }^{1}$, Dae Hyun Song ${ }^{2}$, and Jin Pyeong Kim ${ }^{1}$ \\ ${ }^{1}$ Department of Otorhinolaryngology-Head and Neck Surgery, Gyeongsang National University College of Medicine, \\ Gyeongsang National University Changwon Hospital, Changwon; and \\ ${ }^{2}$ Department of Pathology, Gyeongsang National University College of Medicine, Institute of Health Science, \\ Gyeongsang National University Changwon Hospital, Changwon, Korea
}

\section{가성대에 발생한 상피 모양 변이 고등급 점액 섬유육종 1예}

송슬기 ${ }^{1} \cdot$ 송대현 $^{2} \cdot$ 김진평

${ }^{1}$ 경상국립대학교 의과대학 이비인후과학교실, 창원경상국립대학교병원,

${ }^{2}$ 경상국립대학교 의과대학 병리학교실, 경상국립대학교 건강과학연구원

\author{
Received April 10, 2021 \\ Revised June 20, 2021 \\ Accepted June 28, 2021 \\ Address for correspondence \\ Jin Pyeong Kim, MD, PhD \\ Department of Otorhinolaryngology- \\ Head and Neck Surgery, \\ Gyeongsang National University \\ College of Medicine, \\ Gyeongsang National University \\ Changwon Hospital, \\ 11 Samjeongja-ro, Seongsan-gu, \\ Changwon 51472, Korea \\ Tel $+82-55-214-2799$ \\ Fax $+82-55-214-1410$ \\ E-mail jinpyeong@gnu.ac.kr
}

Myxofibrosarcoma (MFS) is a histologic subtype of malignant fibrous histiocytoma (MFH), with a predominant myxoid component. MFS is characterized by locally aggressive behavior and a high rate of local recurrence, however, with a good prognosis. Head and neck MFS accounts for 3\% of all cases of MFS. To date, only two cases of laryngeal MFS have been reported. Owing to the rarity of MFS, the clinical characteristics and optimal treatment options remain controversial. Surgical resection with a clear margin is considered the treatment of choice. Compared to traditional MFS tumors, epithelioid variants have worse prognosis. Other factors associated with a poor prognosis of MFS tumors include inadequate surgical margins, large tumor size, old age, and high-grade tumors. Herein, we report a case of high-grade epithelioid variant MFS located in the false vocal fold, requiring total laryngectomy to obtain an adequate surgical margin. To our knowledge, this is the first case report of epithelioid variant of high-grade MFS presenting in the larynx.

Korean J Otorhinolaryngol-Head Neck Surg 2021;64(12):954-8

Keywords Fibrosarcoma; Larynx; Malignant fibrous histiocytoma; Sarcoma; Soft tissue neopla.

\section{Introduction}

Sarcomas account for less than $1 \%$ of head and neck malignancies. ${ }^{1)}$ Head and neck sarcomas represent only $5 \%-15 \%$ of all sarcomas in adults. ${ }^{2)}$ The most common histologic types of sarcomas in the head and neck region are rhabdomyosarcoma, osteosarcoma, malignant fibrous histiocytoma (MFH), and angiosarcoma.

This is an Open Access article distributed under the terms of the Creative Commons Attribution Non-Commercial License (https://creativecommons.org/licenses/by-nc/4.0) which permits unrestricted non-commercial use, distribution, and reproduction in any medium, provided the original work is properly cited.
Myxofibrosarcoma (MFS) is a histologic subtype of MFH that has been previously confused with multiple entities of MFH. The rapid development of immunohistochemical and genetic/molecular studies have established a distinct diagnosis of MFS. ${ }^{3)}$ However, due to the rarity of MFS, the clinical behavior and outcome of MFS tumors are uncertain; moreover, there are no randomized clinical trials to establish treatment guidelines. $^{4)}$

Herein, we report a case of MFS on a false vocal fold, with the patient presenting with voice changes and progressive dyspnea. To our knowledge, this is the first case of high-grade 
MFS in the larynx with an epithelioid variant.

\section{Case}

A 79-year-old male presented to our outpatient clinic with complaints of change in his voice that began one month prior. The patient had no history of smoking or prior irradiation. He suffered from hypertension, diabetes, and cerebrovascular disease with severe stenosis. Laryngoscopic examination revealed a mass-like lesion on the left false vocal fold (Fig. 1A), with intact vocal fold mobility. There were no abnormal findings on esophagogastroduodenoscopy. Initial CT and MRI of the neck revealed a heterogeneously enhancing mass in the left false vocal fold and aryepiglottic fold, with invasion of the paraglottic fat (Fig. 1B and C). However, no definite metastatic lymph node was identified in the neck, bilaterally. Rigid laryngoscopy and punch biopsy of the left false vocal fold mass were performed under general anesthesia. Punch biopsy revealed a spindle cell sarcoma with a myxoid component, suggestive of MFS. There was no distant lesion on positron emission tomography. Even with enough consultation, the patient wanted radiotherapy as a primary treatment. Soon after referring to radiation oncologist, the patient visited the emergency room for dyspnea 5 days after rigid endoscopy and underwent emergent tracheostomy. As the tumor was large and aggressively growing, with involvement of the paraglottic space, and considering patient's characteristics (old age, poor pulmonary function, and multiple co-morbidities), total laryngectomy was performed 1 week after the tracheostomy. Final histopathology confirmed a high-grade MFS, with a maximum tumor diameter of $3 \mathrm{~cm}$. The tumor was composed of spindle cells with a myxoid background (Fig. 2A and B), which did not react with cytokeratin antibody (Fig. 2C). Immunohistochemical staining using vimentin and CD31 was posi- tive (Fig. 2D and E). Partial epithelioid features were identified with vascular invasion (Fig. 3). The aforementioned pathologic results were consistent with a high-grade epithelioid variant MFS. The patient was discharged 14 days after surgery without complications and was followed up for 4 months with no tumor recurrence.

\section{Discussion}

MFS was firstly described as a "myxoid variant of MFH" by Weiss and Enzinger" in 1977. They reported that the myxoid variant of MFH exhibited a better prognosis than other forms of MFH tumors. ${ }^{5)}$ Owing to various efforts to distinguish MFS from a variety of histological types of MFH, as well as advances in immunohistochemistry and molecular techniques, the 2013 World Health Organization Classification of Tumors of Soft Tissue and Bone recommended the use of the term MFS instead of myxoid variant MFH. ${ }^{3)}$ Patients presenting with MFS are generally 50 to 70 years of age and are more commonly men. ${ }^{6}$ The most common site of involvement is the extremities (77\%), with an incidence rate of $3 \%$ in the head and neck region. ${ }^{6-8)}$ Owing to the multidirectional spread of MFS along the facial planes and its infiltrative growth pattern, obtaining a clear surgical margin may be challenging. ${ }^{4}$ For this reason, MRI is the diagnostic modality of choice to identify the extent of the tumor preoperatively. ${ }^{4)}$ Surgical resection is the treatment of choice for patients presenting with MFS. There is no randomized controlled study specific to MFS evaluating the treatment outcome of surgery compared to radiotherapy. The national comprehensive cancer network (NCCN) clinical practice guideline in soft tissue sarcoma recommends surgical wide excision as a primary treatment option when soft tissue sarcoma in head and neck is resectable. ${ }^{8)}$ And one retrospective study reported the patients treated with
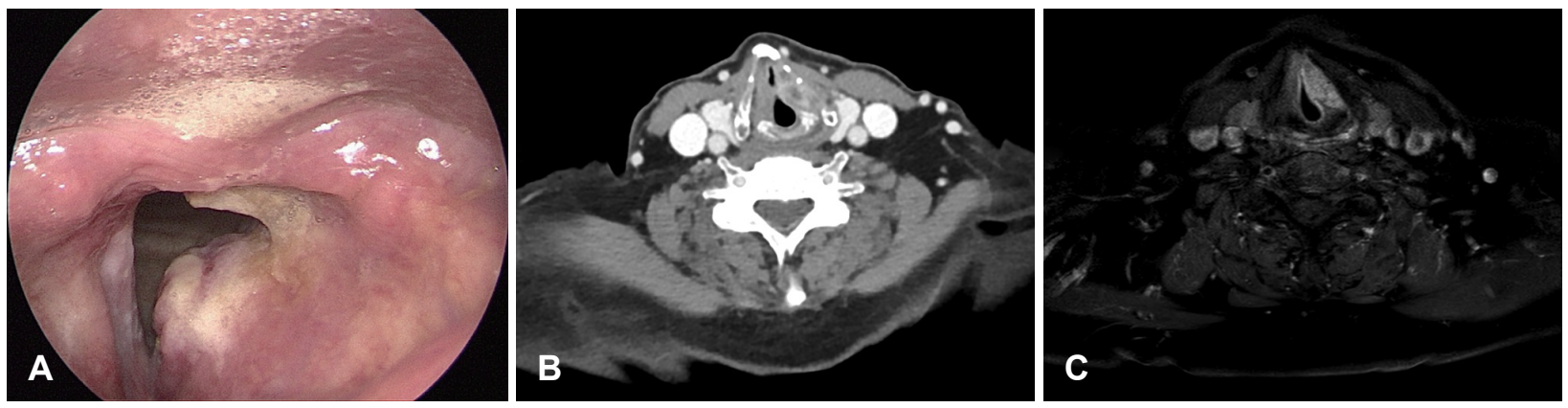

Fig. 1. Preoperative evaluation. A: Laryngoscopic finding, showing a protruding mass in the left false vocal fold. B and C: Preoperative CT image (B) and MR image (C) showing a heterogeneously enhanced mass in the left false vocal fold and aryepiglottic fold, extending to the paraglottic fat. 


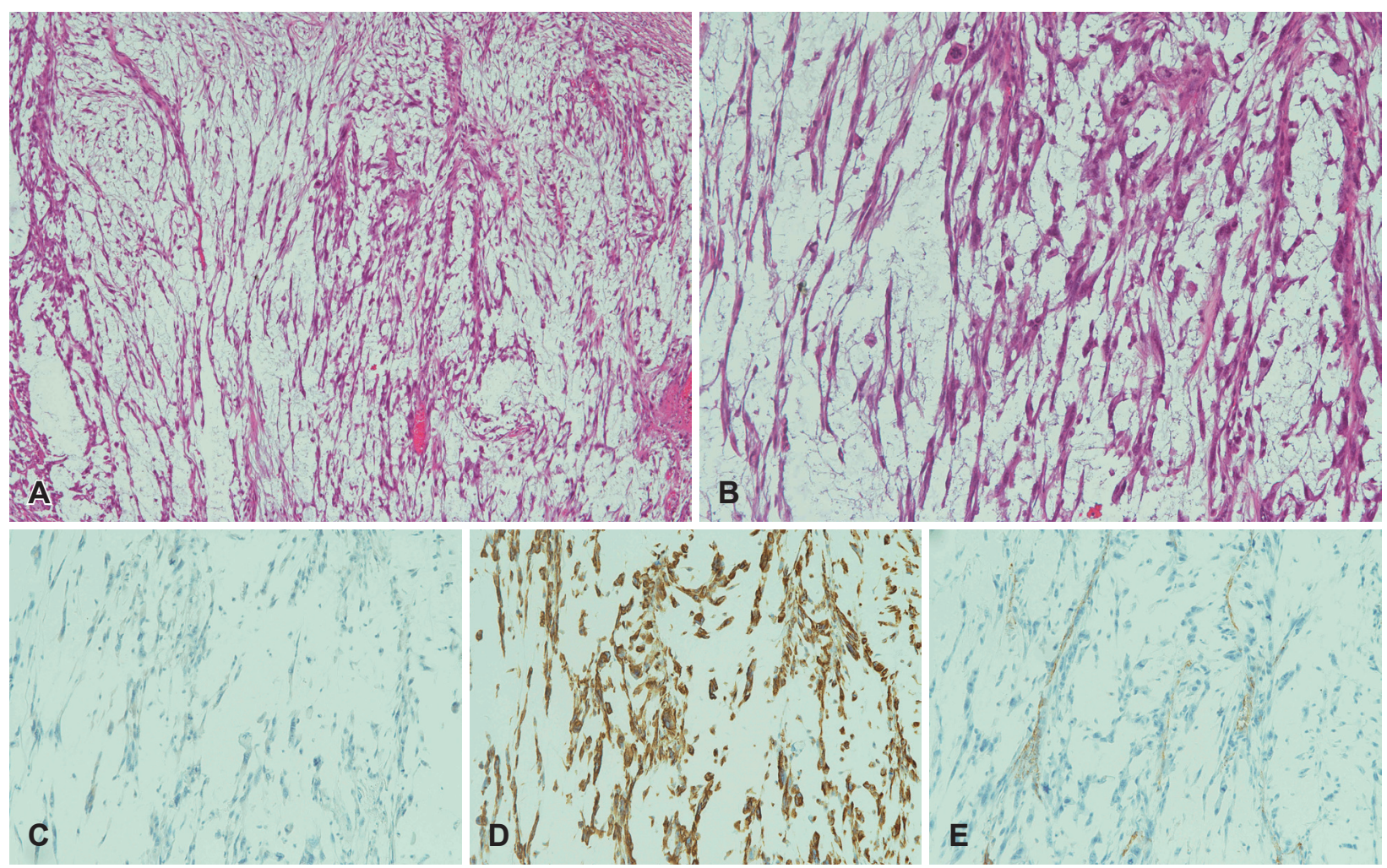

Fig. 2. Postoperative histopathologic and immunohistochemical findings of myxofibrosarcoma. A: The tumor consisted of spindle cells with a myxoid background; elongated, curvilinear, and thin-walled blood vessels are observed among spindle tumor cells (H\&E stain, $\times 40)$. B: Spindle cells showing enlarged hyperchromatic nuclei with eosinophilic cytoplasm (H\&E stain, $\times 100)$. C: Spindle tumor cells with no reaction to cytokeratin antibody (pan cytokeratin, $\times 100$ ). D: Tumor cells with positivity to vimentin antibody (vimentin, $\times 100)$. E: CD31 immunohistochemical stain highlighting distinctive curvilinear blood vessels (CD31, $\times 100)$. H\&E, hematoxylin and eosin.
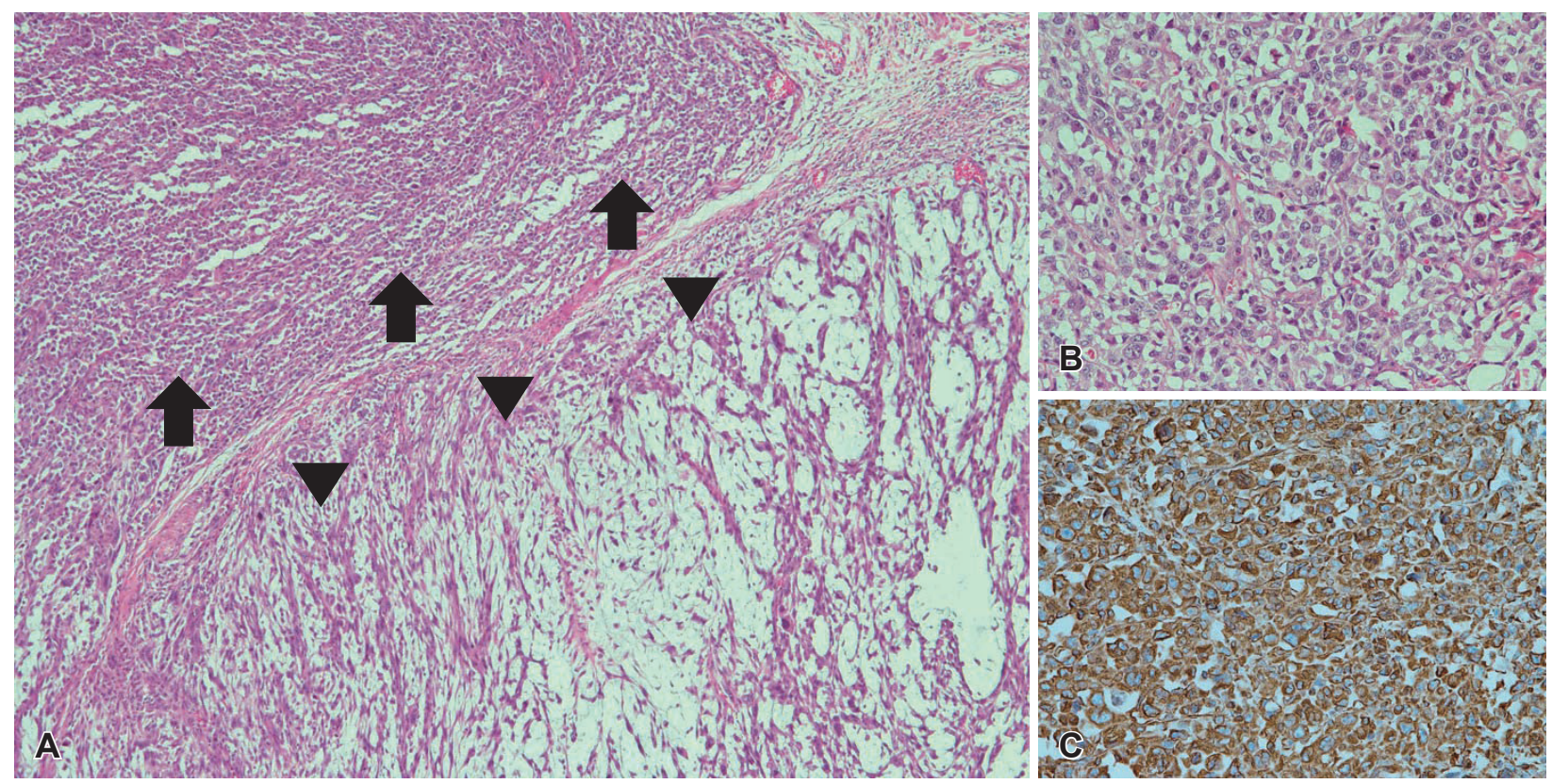

Fig. 3. Postoperative histopathologic and immunohistochemical findings of epithelioid variance. A: Typical histologic background of myxofibrosarcoma (arrowheads) with a partial epithelioid variant (arrows) (H\&E stain, $\times 40$ ). B: Higher power imaging of the region of the epithelioid variant $(H \& E$ stain, $\times 200)$. C: The epithelioid variant portion showing positivity to vimentin antibody (vimentin, $\times 200)$. H\&E, hematoxylin and eosin. 
radiotherapy had the same prognosis as untreated patients. Although radiotherapy as a definitive treatment in MFS seems to have poor oncologic outcome, the neo-adjuvant or adjuvant therapies with surgery have a benefit of reducing potential local and distant recurrences. ${ }^{4}$

MFS has a relatively better prognosis than the other histological subtypes of sarcomas, such as leiomyosarcoma, with the 5-year overall survival ranging from $61 \%$ to $82.6 \%$. However, MFS is a locally aggressive tumor with a high rate of local recurrence of $16 \%-57 \%$ and with a median time to recurrence of $8.2-27$ months. ${ }^{4,9,10)}$ For this reason, wide resection, including a $2 \mathrm{~cm}$ free margin from the tumor, is recommended. Prognostic factors have been investigated, with inadequate surgical resection margins, large tumor size, old age, and high-grade histology found to be significant poor prognostic factors for overall survival. ${ }^{9,10)}$

Various grading systems have been developed for MFS, with the French Federation of Cancer Centers Sarcoma Group system and the National Cancer Institute system being the most widely recognized. These systems include three groups of soft tissue sarcomas, as low-, intermediate-, and high-grade. ${ }^{11,12)}$ The recurrence rate of high-grade tumors is $62 \%$, which is higher than the rate for low-grade tumors $(48 \%){ }^{4)}$ Rarely, epithelioid cells, rather than spindle cells, can be observed within the myxoid area of the MFS, with the epithelioid variant of MFS having a poor prognosis compared to traditional spindle cell MFS. Nascimento, et al. ${ }^{13)}$ reported the epithelioid variant to be more aggressive than the traditional spindle cell MFS, with a rate of local recurrence of $70 \%$ and a rate of metastases of $50 \%$. Scoccianti, et al. ${ }^{9)}$ reported the presence of an epithelioid variant pattern as a negative prognostic factor for disease-specific survival, local recurrence free survival, and metastases free survival. In fact, the reported rate of diseasespecific survival of $53.6 \%$ for the epithelioid subtype of MFS is markedly lower than the survival rate for low-grade $(100 \%)$ and high-grade (77.7\%) tumors. ${ }^{9}$

Gugatschka, et al. ${ }^{14)}$ reported a low-grade MFS in the unilateral vocal fold, which was completely excised by laser cordectomy, with a clear surgical margin. Ocak, et al. ${ }^{15)}$ reported an intermediate-grade MFS on the arytenoid mucosa, with a positive surgical margin achieved after surgery. Our case is the first report of a high-grade MFS with an epithelioid variant in the larynx. In fact, the previously reported laryngeal MFH might be MFS. However, the concept of MFS has been affirmed since 2002, and the cases of MFS in the larynx are extremely rare since then.
Owing to the unique anatomical features of the larynx, wide resection of the tumor with a clear resection margin may be difficult to perform due to the critical negative effect on function, including speech and swallowing. In such cases, free flap reconstruction may be essential. Considering the generally favorable survival outcome for these tumors in relation to the negative impact of wide resection on function, the extent of initial surgery for laryngeal MFS is an issue of controversy. However, owing to the high rate of local recurrence of MFS, wide excision with a clear surgical margin may still be the treatment of choice. In our case, 1) the tumor was aggressively growing and involved the paraglottic space, and 2) the patient had old age, poor pulmonary condition, frequent aspiration tendency, and multiple co-morbidities. Roland, et al. ${ }^{4)}$ recommends wide surgical resection with a $2 \mathrm{~cm}$ soft tissue margin from the area of enhanced signal on T2-weighted MRI, and NCCN guideline also recommends special consideration of resection margin in the infiltrative histologies such as MFS, dermatofibrosarcoma protuberans, and angiosarcoma; therefore, total laryngectomy was inevitable to obtain a clear surgical margin. Final pathologic reports with high-grade and epithelioid variant MFS revealed total laryngectomy might be better option than laryngeal-preserving surgery. Unfortunately, we could not evaluate therapeutic outcome due to too much short follow period, long-term observation is required. Most of laryngeal malignancies originates from epithelium. Laryngeal sarcomas are relatively rare and MFS in the larynx is extremely rare. It is difficult to evaluate the treatment outcome of MFS in the larynx because there have been few studies. Still, much wider excision of tumor in MFS may be recommended than in carcinoma for better local control. Further study is required to elucidate a proper treatment.

\section{Acknowledgments}

None.

\section{Author Contribution}

Conceptualization: all authors. Data curation: Seulki Song. Formal analysis: Jin Pyeong Kim. Funding acquisition: Seulki Song. Methodology: Seulki Song. Resources: Dae Hyun Song. Software: Seulki Song. Supervision: Jin Pyeong Kim. Validation: Seulki Song. Visualization: Seulki Song, Dae Hyun Song. Writing - original draft: Seulki Song, Dae Hyun Song. Writing — review \& editing: all authors.

\section{ORCIDs}

Jin Pyeong Kim https://orcid.org/0000-0001-6137-8232

Seulki Song https://orcid.org/0000-0001-5791-2607 


\section{REFERENCES}

1) Farhood AI, Hajdu SI, Shiu MH, Strong EW. Soft tissue sarcomas of the head and neck in adults. Am J Surg 1990;160(4):365-9.

2) Potter BO, Sturgis EM. Sarcomas of the head and neck. Surg Oncol Clin N Am 2003;12(2):379-417.

3) Fletcher C, Bridge JA, Hogendoorn PCW, Mertens F. WHO classification of tumours of soft tissue and bone. 4th ed. Lyon: IARC Press;2013.

4) Roland CL, Wang WL, Lazar AJ, Torres KE. Myxofibrosarcoma. Surg Oncol Clin N Am 2016;25(4):775-88.

5) Weiss SW, Enzinger FM. Myxoid variant of malignant fibrous histiocytoma. Cancer 1977;39(4):1672-85.

6) Merck C, Angervall L, Kindblom LG, Odén A. Myxofibrosarcoma. A malignant soft tissue tumor of fibroblastic-histiocytic origin. A clinicopathologic and prognostic study of 110 cases using multivariate analysis. Acta Pathol Microbiol Immunol Scand Suppl 1983;282:140.

7) Mentzel T, Calonje E, Wadden C, Camplejohn RS, Beham A, Smith MA, et al. Myxofibrosarcoma. Clinicopathologic analysis of 75 cases with emphasis on the low-grade variant. Am J Surg Pathol 1996;20(4):391-405.

8) Sanfilippo R, Miceli R, Grosso F, Fiore M, Puma E, Pennacchioli E, et al. Myxofibrosarcoma: Prognostic factors and survival in a series of patients treated at a single institution. Ann Surg Oncol
2011;18(3):720-5.

9) Scoccianti G, Ranucci V, Frenos F, Greto D, Beltrami G, Capanna $\mathrm{R}$, et al. Soft tissue myxofibrosarcoma: A clinico-pathological analysis of a series of 75 patients with emphasis on the epithelioid variant. J Surg Oncol 2016;114(1):50-5.

10) Odei B, Rwigema JC, Eilber FR, Eilber FC, Selch M, Singh A, et al. Predictors of local recurrence in patients with myxofibrosarcoma. Am J Clin Oncol 2018;41(9):827-31.

11) Neuville A, Chibon F, Coindre JM. Grading of soft tissue sarcomas: From histological to molecular assessment. Pathology 2014;46(2): 113-20.

12) Russell WO, Cohen J, Enzinger F, Hajdu SI, Heise H, Martin RG, et al. A clinical and pathological staging system for soft tissue sarcomas. Cancer 1977;40(4):1562-70.

13) Nascimento AF, Bertoni F, Fletcher CD. Epithelioid variant of myxofibrosarcoma: Expanding the clinicomorphologic spectrum of myxofibrosarcoma in a series of 17 cases. Am J Surg Pathol 2007; 31(1):99-105.

14) Gugatschka M, Beham A, Stammberger H, Schmid C, Friedrich G. First case of a myxofibrosarcoma of the vocal folds: Case report and review of the literature. J Voice 2010;24(3):374-6.

15) Ocak GA, Ozbudak IH, Toru HS, Derin AT. Second case report of myxofibrosarcoma of larynx. Otolaryngology 2015;5(2):186. 